\title{
The Commodity Flow of U.S. Children's Television
}

\author{
Matthew P. McAllister \& J. Matt Giglio
}

This article argues that commodity flow is a defining characteristic of children's television programming, and that this flow of commodity and corporate-brand images builds into the genre a relatively coherent selling ethos. Three-hour blocks of programming, recorded on two different Saturday mornings for several broadcast and cable networks, were analyzed to highlight commodity flow within and between networks. This flow of commodities on children's television indicates a blurring of the distinction between content and promotional forms and illustrates the high level of commercialism targeted at this audience.

Keywords: Children's Television; Commodity Flow; Advertising; Commercialization; Media Promotion; Media Synergy

Viewers watching the 8:30 am telecast of Rocket Power, a program on the children's cable network Nickelodeon on Saturday, January 26, 2002, may have noticed at its conclusion (at 8:55 am) a common technique called "living end credits." Also called "squeezed credits," these occur when the closing credits are reduced to a small portion of the television screen while the bulk of the screen is used to promote an upcoming program. In this case, however, the promotional space is not used to tout a future Nick show, but features a music video by heartthrob singer Aaron Carter. The song is part of the soundtrack for the film Jimmy Neutron, Boy Genius, at that time still in theatrical release. The Nick logo and the web address nick.com also appear on the bottom of the screen. Four minutes later, at 9:00, a government-mandated "program separator"

Matthew P. McAllister is an associate professor in the Department of Film/Video and Media Studies at Penn State. J. Matt Giglio is an instructor at Virginia Tech. Correspondence to: Matthew P. McAllister, College of Communications, 209 Carnegie Bldg, Penn State, University Park, PA 16802, USA. Tel: 814863 3322; Email: mattmc@psu.edu. An earlier version was presented at the annual meeting of the National Communication Association, Mass Communication Division, Miami Beach, FL, November 2003. Data collection occurred while the first author was a faculty member and the second author an M.A. student at Virginia Tech. The authors thank Dale Kunkel, Mary Beth Oliver, and Edward H. Sewell, Jr. for their insights. They also thank those who assisted with videotaping: Rachel Holloway, Dale Jenkins, Nancy Jurek, Marlene Preston, Liching Sung, Beth Waggenspack, and Emily Wilkinson Stallings. 
(or "bumper") signals that a commercial break is about to start or end. In this case, the program separator airing before Rugrats features the character of Jimmy Neutron controlling an orange robotic monster with a Nickelodeon logo on its head.

At 9:10 am a video "bug" appears for several seconds during the Rugrats program. A bug is a small video icon in the screen's bottom corner; often this identifies the network being watched. In this case, the bug is quite elaborate. Appearing on the screen are the words, "Grab a pencil and paper. Nickelodeon Milk Mustache. Coming up." True to its word, at 9:12 a minute-long spot promotes a contest co-sponsored by Nickelodeon and the dairy industry. The spot states that the winner, along with a Nickelodeon character, will be featured in a "Got Milk?" advertisement in Nickelodeon magazine. When a copy of the magazine is displayed on screen, Jimmy Neutron is pictured on the cover.

Fifteen minutes later $(9: 27 \mathrm{am})$, a traditional spot commercial for the Jimmy Neutron movie airs. A promotion for a Jimmy Neutron computer game available at nick.com airs at 9:44. At 9:56 and 10:26, different versions of the commercial and squeezed credits for Jimmy Neutron air. At 10:58, a milk mustache commercial featuring the video-game character Mario completes the commercial circuit: the ad portrays live-action children interacting with a licensed property, just as promised to potential winners of the Nickelodeon contest.

The Jimmy Neutron example from Nickelodeon, although particularly licensingoriented (Pecora, 2004), is not uncharacteristic of the often-seamless movement of product images and corporate branding that is increasingly a defining element of U.S. children's television. It thus illustrates "commodity flow," a concept that highlights the embeddedness of promotional and commercial techniques throughout television generally but especially in children's television. To explore how the phenomenon applies to commercial programming aimed at children, we first discuss commodity flow as a construct, including its establishment in the work of Raymond Williams (1975). The concept is valuable for deconstructing children's television, given the genre's long-established roots in commercial culture and more current role in media corporate synergy. The existence of different manifestations of commodity flowincluding intra-channel, inter-channel, and synergistic flow-will then be demonstrated by an analysis of specific commodity flow patterns in several hours of children's programming. The analysis shows how the flow of commodities on children's television often blurs the distinction between content and promotional forms, dramatically illustrating the intense level of commercialism targeted at this audience.

\section{From Television Flow to Commodity Flow}

Television executives have probably understood the idea of flow, especially as manifested in audience viewing patterns and programming strategies, since the beginnings of commercial broadcasting. Raymond Williams is largely credited with introducing the scholarly concept of television flow, now one of the most commonly used concepts in television studies (Corner, 1999). Williams argued that television is a technological and cultural experience that brings together discrete phenomena (events that occur outside of the medium in different locales and contexts) by framing them in 
a continuous stream of images and sound channeled through television. Specific techniques such as television program promotions, cliffhangers in programs timed before a commercial break, and strategic program scheduling combine with television's characteristics as a medium to decrease the incongruence between images on the screen and enhance their ability to flow into one other. Content categories such as different program genres and product commercials therefore are enacted not as fragmented and isolated forms but more as the experience of "watching TV." The ease of channel switching (even in the pre-remote control 1970s, when Williams developed the concept), the similarity of program structure, and uniform scheduling on nearly all stations and networks render flow an inter-channel experience, "perhaps the defining characteristic of broadcasting" (Williams, 1975, p. 86).

The idea of television flow has been critiqued and transformed. Modleski (1983), for example, argues that flow does not adequately explain all television genres and "dayparts" (an industry term for sections of the broadcasting day), especially daytime television, which she contends is characterized by repetition and interruptability, to match the reception context of stay-at-home wives and mothers. Similarly, Corner (1999) regards Williams' concept as undertheorized and often misapplied. He concludes that over-zealous use of flow essentializes the medium and masks fundamental differences in its programming forms.

Revisionists also contend that Williams attributed too much agency to the technology of television in his explanation of flow, therefore downplaying the influence of economic factors (Corner, 1999). The "product" of commercial television is, after all, the audience, which the television industry sells to advertisers (an idea first attributed to Smythe, 1977). Viewers who switch channels or turn the television off can no longer be sold to advertisers. It is in the best economic interests of television, then, to reduce the disjointed nature of the transition between "switchable" moments, such as when a program breaks to a series of commercials, and thus keep viewers in their television place.

Budd, Craig, and Steinman (1999) point out another increasingly important way that advertisers influence television flow. They argue that the "flow of commodities," characterized by the similarity of specific elements in product commercials, promotional spots, and programs, is intended not just to keep an audience in front of the television, but also uses all possible televisual forms to sell, including but not limited to the traditional 30-second spot commercial. Their analysis of one night's broadcast of CBS, for instance, identifies such commodity-flow characteristics as the presence of one actor both as a character in a program and as a narrator for a commercial that airs during the program, and product placements.

Budd et al.'s (1999) emphasis on the pervasiveness of commodity flow is well aligned with other critiques of the increased level of commercialism in broadcasting (Andersen, 1995; Jacobson \& Mazur, 1995; McAllister, 1996). These scholars argue that, beginning in the mid-1980s, television advertising was plunged into crisis as several developments unfolded. These included: (1) dissemination of technologies like the remote control and personal recording devices that facilitate viewers' avoidance of discrete commercial spot advertisements; (2) increased competition for viewers from 
cable, video games, and other sources that eroded traditional television network viewership; and (3) the large number of television commercials/promotions ("clutter") that may undermine the effectiveness of any single television spot ad. The result was an increased aggressiveness on the part of advertisers. In this context, television's commodity flow is cultivated when advertisers try to prevent viewer zapping, enhance the promotional power of ad campaigns with the help of increasingly accommodating television networks, and create connections between ads and beloved programs to help campaigns stand out from the clutter. Resulting examples of commodity flow on primetime television include college football bowl sponsorships, "long-form" advertisements like infomercials, and aggressive product placement in such genres as reality-based programs.

Adding to the increased influence of commercial product flow on television are the synergistic strategies of many key corporations involved with the television industry. The increased emphasis on media promotion is one side-effect of the growth of large media entertainment conglomerates (see, for example, Bagdikian, 2004; McChesney, 1999). Corporations owning different media outlets often exploit promotional and licensing linkages between the properties to create corporate efficiencies. Television holdings, then, may be used to promote (and be promoted by) music, book, film, and other media subsidiaries. As manifested by such synergistically driven companies as Time Warner, Disney, Viacom, and News Corp., the temptation to create a "promotional flow" among different programming and commercial elements may be as great as-and complementary to-commodity flow driven by advertisers (McAllister, 2000).

A more salient example of this phenomenon is found in children's television, an especially commercialized genre of television, both historically and in the current hyper-promotional environment. The next section briefly discusses traditional connections between advertising and children's programming, as well as recent trends in synergistic ownership of children's media.

\section{Children's Commercial Television in Historical and Corporate Contexts}

Early children's programming was in many ways more crassly (if less strategically) influenced by advertising's influence than later versions. Advertisers began aggressively using the medium to sell directly to kids at least by the mid-1950s with the success of the Mickey Mouse Club to promote Disney and other brands (Kline, 1993).

Many early TV ads targeted at children in retrospect were highly "flow oriented." Sponsorship of programs by one dominant advertiser was common. In the late 1950s, for example, Kellogg Company owned the syndicated Huckleberry Hound (Mittell, 2003). Over $60 \%$ of children's programs sampled from the 1950 s contained sales pitches by the program's host for sponsored products. These programs routinely used "integral ads" (seamless commercial messages in the program featuring established program characters) and "segue ads" (touting of products by program actors, but often in a neutral setting and conducted between program segments or before a more circumscribed commercial break) (Alexander, Benjamin, Hoerrner, \& Roe, 1998). 
Legislation eventually banned practices such as explicit host-selling. Nonetheless, other commercial and promotional techniques encouraged commodity flow. Fastfood restaurants, breakfast cereals, and other products are sold on children's television, but it is perhaps the toy industry that is the most integrated in the programming mix. Describing the relationship as symbiotic, Pecora (1998) says the "programs offer the toy industry advertisements for characters, and the toys present the entertainment industry with readily identifiable characters" (p. 40). Creating toys that feature licensed characters - characters that appear in a variety of program and commodity forms-allows advertisers to grab the child viewers' attention and break out of commercial clutter (Seiter, 1993). In 1997, approximately half of all toys were based on licenses from television or movies (Kapur, 1999). This also works in the other direction: beginning in the 1980s programming based upon toy and game characters became common (Pecora, 1998). Significant money is at stake. In 2000-2001, advertising on children's network television earned \$700-750 million a year for the cable and broadcast networks (Larson, 2001). This figure actually underestimates the value of children's television programming, given the promotional benefits this provides its corporate owners. As a market, children in the 4-12 age group directly control as much as $\$ 29$ billion a year, and influence family purchases in the $\$ 290$ billion range (McDonald \& Lavelle, 2001), including media products such as DVDs.

Four corporate giants have been especially involved in producing and distributing children's television to tap the advertising and media-product purchasing potential of this market. Typically owning both a broadcast and cable outlet for their programming, these corporations use a synergistic philosophy to build multi-media brand identity. These four are briefly profiled below.

- News Corp, via its Fox Kids Network programming block, was a dominant player in the 1990s, triggered by its embrace of the Power Rangers franchise earlier that decade (Kinder, 1999; Pecora, 1998). Fox's audience share dwindled in the early 2000s and the network's sale of the Fox Family Channel to Disney in 2001 left it without the potential for all-important cable/broadcast "cross-platform promotions" (quoted in Bernstein, 2001, p. 30).

- Viacom, through its Nickelodeon cable network and franchise, was the ratings leader after the Fox drop-off, and is one of the top-rated U.S. cable networks of any type (Sandler, 2004). Nickelodeon often uses its corporate siblings such as Paramount to carry and promote licensing. CBS, also owned by Viacom, typically programs an abbreviated block of children's shows on Saturday morning, most of it heavily influenced by the Nickelodeon brand.

- Disney is, of course, a visible force in children's television, using $\mathrm{ABC}$ to reach younger child viewers early in its schedule, and its cable networks The Disney Channel and ABC Family (bought from Fox) to attract the slightly older "tween" market (Dempsey, 2001a). Although the Disney Channel is "commercial-free," it is hardly promotion-free: It generates revenue from cable license fees, licensing/ merchandising activity, and sponsorship deals (Schmuckler, 2002). 
- Time Warner uses both its cable-based Cartoon Network and its broadcasting subsidiary Kids WB to compete for the market. Each of these TW outlets is a separate entity with its own organizational culture, but the goal is to develop synergistic projects and approach advertisers as a combined unit (Bernstein, 2001; Schmuckler, 2002). In fact, the two networks frequently share or "repurpose" each other's programs (Sandler, 2003, p. 102).

Commodity flow in children's television is not wholly without constraints. Applying to both broadcast and cable (Kunkel \& McIlrath, 2003), the Children's Television Act of 1990 established restrictions on the amount of "commercial time" during children's television (10.5 minutes per hour on weekends; 12 minutes per hour on weekdays) and broad requirements for the airing of children's educational programming. Host-selling and program-length commercials are prohibited; bumpers between programs and commercials are required. However, several loopholes in this Act, as well as recent media developments, leave much room for the cultivation of commodity flow, as will be illustrated. For example, the ambiguities embedded in the definitions of both commercial time and educational programming problematize the effectiveness of such measures (Kinder, 1999; Kunkel, 2001). Public service announcements (PSAs) and program promotions-both of which can incorporate commodity imagery-are not considered advertising by the Act (Kunkel \& McIlrath, 2003). In addition, the definition of program-length commercial used by the Act, a result of policy compromise, essentially restates the definition of host-selling: "a program associated with a product in which commercials for that product are aired" (quoted in Kunkel, 2001). Programs based upon toys and media licenses, then, are perfectly legal, as long as ads for those same products do not air during the program on that same channel. On that same channel, it will be argued, becomes a significant factor in the modern multi-channel environment. Although their existence is mandated, bumpers can become tools for, rather than against, "connected selling" in a medium dominated by corporate branding.

\section{Method}

To capture the possibilities for commodity flow in children's television, several hours of programming from five different networks were taped and analyzed on two separate dates. Three continuous hours of programming (from 8 am to $11 \mathrm{am}, \mathrm{EST}$ ) were collected on Saturday, July 29, 2000, and Saturday, January 26, 2002, for a total of 30 hours. Two different time periods were chosen to prevent analyzing an atypical historical moment, such as the highly commodified Pokémon craze in the late 1990s. In addition, two seasons, summer (from 2000) and winter (2002), were selected to avoid a sample skewed by calendar-based promotions or contests. The five networks (three cable and two broadcast) videotaped were ABC, Cartoon Network, FOX, Nickelodeon, and the WB. These five networks were chosen for study, given their uninterrupted three-hour block of children's programming (unlike NBC or CBS), their stable nature (unlike the troubled Family Channel, see Dempsey, 2001b), and their acceptance of product advertising (unlike PBS or The Disney Channel). 
Tapings were coordinated so that analysis began at exactly $8 \mathrm{am}$, to enable crosschannel comparisons of images and content types. The authors took detailed notes about iconography, sounds, language, and other textual characteristics. They also noted the beginning and ending time of the discrete units of content types found on children's television: program credits, program segment beginning and endings, program separators, product commercials, promotional spots for programs, network and station IDs, and PSAs. The resulting 131 pages of single-spaced notes were then extensively re-read and compared to uncover points of convergence and emerging themes and groupings. Moreover, video tape segments were often viewed again to expand the analysis. ${ }^{1}$

Guiding the analysis of the programming and the subsequent notes was the idea of commodity flow, the main "sensitized concept" of the study. Sensitized concepts are "taxonomical systems that discover an integrating scheme within the data themselves" and facilitate analytical focus in qualitative research (Christians \& Carey, 1989, p. 370). Using commodity flow as a significant sensitized concept enabled a focus on connections between content categories, especially when these connections involved commercial and promotional forms. These connections were then used to generate styles and categories of commodity flow. Various forms in the enhanced commercial and synergistically promotional environment of children's television often blur the distinctions among traditional content types, different networks, and even different media. The remainder of this article analyzes three kinds of commodity flow emerging from the programming: intra-channel commodity flow, inter-channel commodity flow, and synergistic commodity flow.

\section{Intra-Channel Commodity Flow}

Among the most common of the commodity flow categories found during the telecasts was intra-channel commodity flow, where commodity images are interwoven throughout the line-up of one network. The researchers found several sub-categories of intra-channel commodity flow.

\section{Shared Textual Elements Between Programs and Commercials}

Seiter (1993) notes that children's television commercials are "rapidly paced, musical, and filled with special effects and animation. Children behave raucously, outsmarting adults and escaping the dull restrictions of home and school" (p. 3). This, of course, also describes much of the children's programming that airs between the commercials. The visual styles and sounds of commercials and children's programs are strikingly similar.

Animation, obviously, is a common modality found throughout children's television. Often, the specific style of the animation of commercials matches that of other content types such as programs, program promos, and program separators. For example, in the $2002 \mathrm{ABC}$ sample, similar visual styles mark the 8:00 am cartoon program Mary Kate and Ashley in Action! This program features the animated 
adventures of the Olsen twin sisters as secret agents, but the beginning and end of the program are live action segments featuring the actors Mary Kate and Ashley Olsen. This mix of live action and animation continue in a program separator at 8:27:35, which presents a live-action small girl (about the same age as Mary Kate and Ashley) dancing with an animated "1" (as in "Disney's 1 Saturday Morning," the network's branding slogan at the time). Immediately following, at 8:27:41, a commercial for Honeycombs cereal airs, with a plot involving a live-action snowboarder morphing into the animated Honeycomb "Craver." This is followed at 8:28:11 by a Three Musketeers candy bar ad, where the animated Musketeers accept a "Chocolately Award" at a live-action ceremony. Following this is a 15-second promotion for Disney's Teacher's Pet (all animated), back to the girl-dancing program separator, and then finally the life-action epilogue with Mary Kate and Ashley. Similar matching of styles continues throughout Saturday morning.

Sounds between commercials and other program types also match. In primetime television, the sound difference between programs and commercials is often

Table 1 List of Children's Morning Programs Shown or Promoted on FOX during the Time Sampled (in order of first appearance)

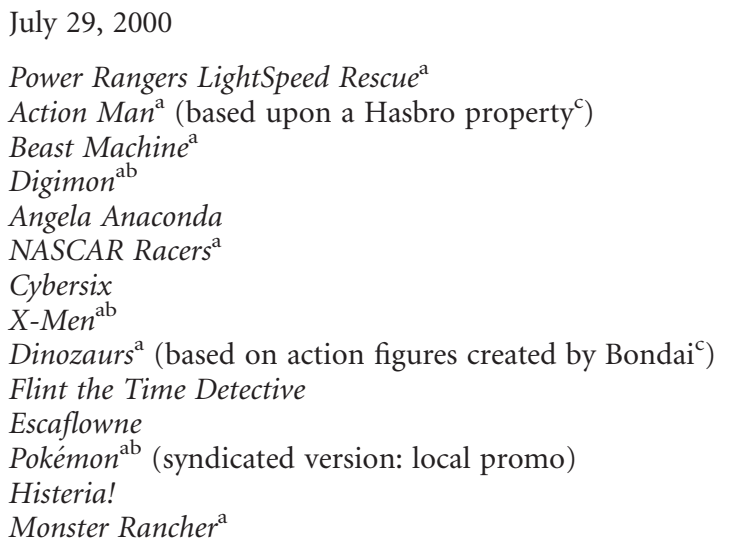

${ }^{\mathrm{a}} \mathrm{A}$ program that is heavily commodity-oriented through licensing activities in the U.S.

${ }^{\mathrm{b}} \mathrm{A}$ program with specific characters also used in commercials or other forms to promote product licensing during telecast.

${ }^{\mathrm{c}}$ From Hall (2000).

${ }^{\mathrm{d}}$ From Finnigan (2002). 
M. P. McAllister \& J. M. Giglio

significant. Adult television programs tend to be fairly sedate in terms of music and sound effects; the ads feature such elements more prominently. However, jarring sound effects and loud rock or hip-hop music are much more common in children's programming, matching the surrounding commercials. Sounds of conflict and strident music may be found in action-adventure cartoons and commercials for toys, such as a sequence on FOX 2002 that featured violent conflict and action music in a Power Rangers Time Force episode (8:31), a Lego commercial featuring Star Wars characters (8:34) and a promo for the spin-off Power Rangers Wild Force (8:35).

Similarly, the role of laughter varies more widely in primetime content forms than in children's television. Most primetime situation comedies feature a laughtrack or live audience reactions, an audio characteristic missing in most commercials. Alternatively, laugh tracks from real or virtual audiences are absent from children's programming, matching their absence in the ads. Tellingly, though, children's laughter itself (emanating from characters) is found in nearly all content forms, including programs and ads, depending upon the target demographic. One such example was a two-minute stretch on ABC 2002 that featured similar sounds of children laughing/playing on the opening credits of the Recess program, and the subsequent $\mathrm{ABC}$ program separator and Kool-Aid commercial.

Table 2 List of Saturday Morning Programs Shown or Promoted on the WB during the Time Sampled (in order of first appearance)

July 29, 2000

Batman/Superman Adventures ${ }^{\mathrm{a}}$

Pokémon $^{\text {ab }}$

Men in Black ${ }^{\mathrm{a}}$

Cardcaptors $^{\mathrm{a}}$

Batman Beyond ${ }^{\mathrm{a}}$

Detention

January 26, 2002

Cubix ${ }^{\mathrm{a}}$

Jackie Chan Adventures ${ }^{\mathrm{a}}$

Pokémon ${ }^{\mathrm{a}}$

Static Shock ${ }^{\mathrm{a}}$

Scooby-Doo a

Magic Schoolbus (local promo for a program on a competitor station)

The Mummy ${ }^{\mathrm{a}}$

X-Men:Evolution ${ }^{\mathrm{a}}$

R.L. Stine's The Nightmare Room ${ }^{\mathrm{a}}$

$Y u-G i-$

$O h !^{\mathrm{a}}$

${ }^{a}$ A program that is heavily commodity-oriented through licensing activities in the U.S.

${ }^{\mathrm{b}} \mathrm{A}$ program with specific characters also used in commercials or other forms to promote product licensing during telecast. 


\section{Programming Featuring Licensed Characters}

Virtually all Saturday morning programming involves licensing to some degree. Even a commercially sedate program like Doug (aired in 2000 on ABC at 8:30 and 9:00 am) has been available in video games (for Game Boy), theatrical film (with the franchisehopeful title Doug's 1st Movie), video tapes, and books (well over 20 different titles).

Much Saturday morning programming is more definitively embedded in ancillary licensing. Many of these programs have their roots in video games, toys, or other merchandise. The WB and Fox in particular aired programming spun off from licensed commodities (see Tables 1 and 2). Nearly $80 \%$ of programs aired or promoted during the period sampled were based upon characters with strong ties to other media or commodities, including comic books (Batman/Superman Adventures, Static Shock, X-Men), movies (The Mummy, Alienators: Evolution Continues, Jackie Chan Adventures), book series (R. L Stine's The Nightmare Room), and toys (Transformers, Action Man, Dinozaurs).

Strikingly commodified are Pokémon and variations of this model, such as Digimon, Monster Rancher, Medabot, Cubix, Mon Colle Knights, Yu-Gi-Oh!, and Card Captors. Pokémon, a dominating brand in the child market from 1996 to 2001 (Tobin, 2004), represents the genre; plots ask characters to collect items such as cards or small

Table 3 Flow of Digimon Images, Fox, July 29, 2000

\begin{tabular}{|c|c|}
\hline Time & Image \\
\hline 8:13:02 & $\begin{array}{l}\text { Promotion for Digimon summer reruns, framed with } \\
\text { FoxKids logo (:20 seconds) }\end{array}$ \\
\hline $8: 23: 58$ & Promotion for Digimon summer reruns \\
\hline $8: 34: 36$ & $\begin{array}{l}\text { Product commercial for Digimon website, which shows Digimon-licensed } \\
\text { merchandise available in eight different product categories (:25 seconds) }\end{array}$ \\
\hline 8:41:51 & Promotion for Digimon summer reruns \\
\hline 8:49:20 & $\begin{array}{l}\text { Promotion for FoxKids Digimon The Movie tie-in contest (:40 seconds); winners } \\
\text { receive "Digimon Game Guide" }\end{array}$ \\
\hline 8:50:20 & Promotion for Digimon summer reruns \\
\hline $8: 57: 27$ & $\begin{array}{l}\text { Promotion in bug: Digimon character appears in bottom corner during the program } \\
\text { NASCAR Racer (:10 seconds) }\end{array}$ \\
\hline 9:00:01 & Program: Digimon first episode begins (:30 minutes) \\
\hline 9:14:37 & Promotion for Digimon upcoming season (:20 seconds) \\
\hline 9:17:34 & Promotion: Digimon character appears in promo for foxkids.com website \\
\hline 9:28:27 & Promotion during credits, for Digimon summer reruns \\
\hline 9:43:17 & Promotion for Digimon summer reruns \\
\hline 9:43:37 & Promotion: Digimon character appears in promo for foxkids.com website \\
\hline $9: 51: 16$ & Promotion of FoxKids Digimon The Movie tie-in contest \\
\hline 10:10:05 & Promotion for Digimon summer reruns \\
\hline $10: 20: 50$ & Promotion of FoxKids Digimon The Movie tie-in contest \\
\hline $10: 27: 10$ & $\begin{array}{l}\text { Promotion in Bug: Digimon character appears in bottom corner during the program } \\
\text { Monster Rancher (:10 seconds) }\end{array}$ \\
\hline $10: 30: 39$ & Program: Digimon second episode begins (:30 minutes) \\
\hline $10: 43: 30$ & Promotion for Digimon upcoming season \\
\hline $10: 57: 57$ & Promotion: narrator promotes Digimon upcoming season during closing credits \\
\hline
\end{tabular}


creatures (Pokémon is an abbreviation of "Pocket Monster"), with the outcome of a key competition or even the fate of the world often hanging in the balance. In the programs these items are magical; in real life they are for sale. Specific plot points often emphasized the importance of amassing large collections (à la the Pokémon brand slogan "Gotta Catch 'Em All”). In a Pokémon episode on the WB 2000, one character states explicitly, "The more Pokémon you have, the better position you are in to win battles." Given the emphasis on collecting implied in nearly all of the above listed cartoons, the programs function as virtual commercials for the licensed collectables featured in the cartoons and related subsidiary properties.

One commodity flow element driving this point home was the use of multiple content forms to create a flow of licensed programming icons on a given network. As promoted programs and advertised products and cross-promoted/cross-mediated characters, images from licensed properties are sprinkled throughout the lineup. An example of this is seen in Table 3, which lists the promotional and commercial moments aired between 8:13 and 10:58 am for Digimon, which in July 2000 was Fox's highest rated children's program (Hall, 2000). The promotions and product commercials create a steady flow of licensed images that connect the Digimon program with the Digimon website, the then-upcoming Digimon the Movie, Digimon video games, the brand identity of FoxKids, its website, and the various programs that Digimon promotions are connected to through "bug" symbols. Although only promotions for the Digimon television program aired during the Digimon program (i.e., no product commercials, thus fulfilling the letter of the Children's Television Act of 1990), the multi-licensed commodity orientation of the Digimon brand makes such distinctions irrelevant. Indeed, some forms, such as a "promotion" for the FoxKids Digimon the Movie tie-in contest, are difficult to classify. It could be legitimately labeled both a promotion for Digimon on FoxKids and an advertisement for the Digimon movie.

\section{Programming Icons in Commercials}

While the above practice integrates the commercial function into programs, another strategy creates "camouflaged ads" (McAllister, 1996) by making product commercials look like programs. A primary mechanism for this is integrating television program characters into these product commercials.

For example, an ad for "The New Rugrats Edition Gateway Astro PC” (at 10:43:29) that aired on Nickelodeon during a 2000 installment of Spongebob Squarepants - and one that is part of a larger cross-promotional campaign between network and advertiser (Sandler, 2004)—uses clips and sounds from Rugrats. Although the commercial itself combines animation and live action, it begins with animation directly lifted from a Rugrats episode; the first sounds heard are the title music that also begins the program. The ad uses seven different clips from Rugrats, all intercut between live-action clips of a little girl laughingly using her Rugrats-branded personal computer. An episode of Rugrats had concluded on the network just 43 minutes earlier. Similarly, in 2000 a cross-promotional ad for Pokémon toys at Burger King 
featuring Pokémon animation aired on the WB in 2000-also carrying Pokémon the network program - and on the local FOX affiliate that also carried Pokémon the syndicated program. At 9:12 am in 2000, the Cartoon Network characters Cow and Chicken appear in a Got Milk ad on that network.

Kunkel \& McIlrath (2003) argue that some product advertising may mask selling intentions by resembling the more benign public service announcement (PSA). PSAs likewise can be integrated into the larger licensed promotional flow of children's television. Resembling both the Fox cartoon NASCAR Racer and promotions for the program, a "wear your seatbelt" PSA aired on Fox 2000 (10:33 am, 90 minutes after the program ended) integrates icons, footage, music, and sounds of the cartoon with a message from real-life NASCAR racer Jeff Gordon and stock footage of a NASCAR race. Gordon is visually framed by a FoxKids graphic and wears his racing outfit, which prominently displays sponsor logos such as Pepsi and GMAC. The PSAessentially a promotion for the cartoon, NASCAR, and its merchandise and sponsors-ends with the same group voice from the cartoon's opening credits that shouts "NASCAR!" As a PSA, it is not counted toward the commercial limits imposed by the Children's Television Act of 1990.

\section{Inter-Channel Commodity Flow}

Although a significant part of television scheduling and advertising placement is still premised on the idea of the "lazy viewer," the remote control and channel surfing that results has nevertheless affected much programming placement strategy (Bellamy \& Walker, 1996). Channel surfing by potentially short-attention-span child viewers is assumed to occur especially frequently. The same commercial is sometimes placed on different channels at the same time to try to "roadblock" those trying to escape ads via the remote control (McAllister, 1996).

With children's television, it is unclear how much inter-channel placement results from strategy, and how much is a matter of sheer redundancy. Many advertising and merchandising campaigns purchase multiple placements on the networks, so that even active channel surfers cannot avoid these ads. One common advertisement found during the 2002 sample, for instance, was for MVP2: Most Vertical Primate, a direct-toDVD movie about a skateboarding chimpanzee (and sequel to Most Valuable Primate, about a hockey-playing chimpanzee). This advertisement aired 21 times during the three-hour sample across the five networks: ABC (six times), Cartoon (two), FOX (six), Nickelodeon (two), and WB (five). Inevitably, then, a roadblock, whether intentional or not, occurred on four of the six networks during one four-minute stretch: This ad appeared at 8:47:16 on WB; 8:50:09 on ABC; 8:51:07 on FOX; and 8:51:10 on the Cartoon Network.

This inter-channel commodity flow across networks was also true not just for one ad placed many times, but also for licenses that appear in many promotional forms. In 2002, 15 minutes before a promotion for The Flintstones program on the Cartoon Network, its sibling the WB aired a Fruity Pebbles cereal ad featuring Fred and Barney in a commercial mock-up of another program, Survivor. More extensive was 
M. P. McAllister \& J. M. Giglio

Pokémon, still a hot property during the 2000 sample. Commercials for Pokémon products and for cross-promotional activities with fast-food restaurants as well as promotions for movies and TV were ubiquitous on the five-channel schedule of the sample. Table 4 focuses on 12 minutes when an active channel surfer could view promotional iconography of Pokémon on all five cable networks. Forms include ads for Pokémon products (a trading card league) and media extensions (the movie version), a promotional spot for the program, and tie-ins in advertisements for Burger King and the snack food Fruit by the Foot. Perhaps exploiting the potential for these multi-channel lead-in promotions, Pokémon the program begins a half-hour later on the WB.

\section{Synergistic Commodity Flow}

Besides the encroachment of product advertisements on other content categories in children's television, another influence on commodity flow is the corporate interests of the network's conglomerate owner. As noted earlier, all five networks studied are owned by entertainment media corporations. These corporations advocate promotional synergies, whereby any given property is used to promote other properties or an overarching corporate brand. Such activity adds a layer of media product promotion upon the traditional toy, cereal, and snack food product commodity flow in children's television. This strategy was especially evident for the corporations with significant multi-media branding targeted at children: Disney, Viacom, and Time Warner.

Disney has been especially aggressive in using its broadcasting and cable outlets to create a corporate brand. Many critics accuse Disney of appropriating culturally rich stories through corporate ownership and then transforming these texts into ideological visions of life that connect to the interests of corporate capitalism and patriarchy (see, for example, Giroux, 2001). Often the specific texts that Disney is accused of appropriating are classic fairy tales, such as Snow White and Cinderella. However, Disney stamps its identity on more recent cultural materials as well. As Table 5 shows, most of the $\mathrm{ABC}$ programs shown during the sample have a possessive

Table 4 Pokémon Iconography “Roadblock” on Five Networks, July 29, 2000

\begin{tabular}{|c|c|}
\hline $8: 21: 42, \mathrm{ABC}$ & $\begin{array}{l}\text { Commercial with cross-promotion } \\
\text { (Burger King ad with a Pokémon the Movie tie-in) }\end{array}$ \\
\hline 8:27:40, WB & Program promotion (Pokémon mentioned as part of summer line-up) \\
\hline $8: 28: 15$, NICK & Commercial for licensed product (Pokémon Trading Card League) \\
\hline $8: 28: 52, \mathrm{CN}$ & Commercial for licensed product (Pokémon Trading Card League) \\
\hline $8: 29: 10, \mathrm{WB}$ & $\begin{array}{l}\text { Commercial for cross-promotion and licensed product } \\
\text { (Pokémon video game shown in a } \\
\text { Fruit-by-the-Foot tie-in with Nintendo) }\end{array}$ \\
\hline $8: 33: 36$, FOX & $\begin{array}{l}\text { Commercial with cross-promotion } \\
\quad \text { (Burger King ad with a Pokémon the Movie tie-in) }\end{array}$ \\
\hline
\end{tabular}


modifier in their title: "Disney's —." This title characteristic explicitly signals Disney's ownership and connects the brand identity of the corporation with the specific program. This is true even for a program like Doug, which originally aired on Nickelodeon in 1991. Disney's name in the altered official title of the program, the result of a production company purchase in 1996, may be legally correct. However, the title Disney's Doug symbolically overwhelms the important role and original authorship of the program's creator, Jim Jinkins.

Even the other non- "Disney's" programs on ABC's Saturday morning schedule ultimately have their own synergistic purpose. Sabrina, the Animated Series (the title of which connotes "spin-off") in 2000 helped to plug the primetime Sabrina, the Teenage Witch, at that time still airing on ABC. In 2002, Mary Kate and Ashley in Action! helped create an inter-channel flow, as other Olsen programs like Two of a Kind and So Little Time were shown on the ABC Family Channel. Two of a Kind on ABC Family aired at 7:30 am, immediately before its cartoon equivalent on $\mathrm{ABC}$, creating a quasi-interchannel lead-in. Lizzie McGuire and Even Stevens are "Powered by Zoog," as ABC program separators and other promotions informed viewers. "Zoog" was a "tweentargeted” programming brand strongly tied with The Disney's Channel's lineup. Both Lizzie and Stevens were shown on ABC and The Disney Channel during this time. One ABC promotional spot (10:54) tells viewers that Lizzie McGuire may also be found on The Disney Channel: this promotion aired about a half-hour after the ABC version of the program ended. Thus, a paradox in the new synergistic media environment is the promotion of a cable network by a broadcast network owned by the same corporate owner, essentially urging viewers to switch channels.

Other content forms besides the programs tout the Disney brand on ABC Saturday mornings. In 2000, the interstitial programming "Disney's One Saturday Morning" promoted Disney and featured Disney characters like Timon and Pumbaa from The Lion King in short skits. In a very similar manner, the shorter program separators (with a narrator saying "Disney's One Saturday Morning will be right back" and the word Disney prominently displayed) do not separate Disney content from the Disney ads and Disney promotions at all. Instead, they become modern versions of "segue ads" from the 1950s, playing up the Disney brand and connecting programs to more conventional forms of commercial culture. ABC telecasts commercials for Disney products (Atlantis on DVD, 2002, for example) and promotions for Disney programs

Table 5 ABC’s Program Line-Up, 8-11 am, July 29, 2000 and January 26, 2002

\begin{tabular}{ll}
\hline $2000^{\mathrm{a}}$ & 2002 \\
\hline Disney's Recess & Mary Kate and Ashley in Action! \\
Disney's Doug & Disney's Teacher's Pet \\
Disney's Recess & Disney's Recess \\
Disney's The Weekenders & Disney's Recess \\
Sabrina, The Animated Series & Lizzie McGuire \\
& Even Stevens \\
\hline
\end{tabular}

anterstitial programming ("One Saturday Morning”) filled the remainder half-hour. 
(Disney's Mickey Mouse Works on ABC, which aired after 11 am that day and therefore not part of the sample) to fill any potential void in the flow of Disney branding. As Table 6 illustrates, in the 2002 broadcast nearly all content types (with the exception of the few PSAs) mentioned or showed Disney, often quite extensively. This, then, creates a promotional flow whereby Disney's name is displayed or uttered 178 times during the three-hour span, nearly once a minute in ads, promotions, and programs. ABC essentially becomes, at least on Saturday mornings, a Disney branding channel.

Other networks also use their children's daypart to promote synergistic holdings. The Nickelodeon/Jimmy Neutron example cited earlier highlights the influence of synergy in that venue. For Time Warner holdings, an ad for Pokémon the Movie 2000 airs on the Cartoon Network 2000 (9:26) at the same time that the Pokémon program is shown on the WB. This strategy subverts restrictions against program-length commercials and host-selling by using two different channels to link product (the movie) to the program. In addition, synergy was at the heart of the Pokémon property for Time Warner, creating an added incentive. Warner Brothers Pictures and Nintendo were involved with the production/distribution of Pokémon the Movie 2000. Meanwhile, Atlantic Records, a subsidiary of Time Warner, produced the sound track, which is also touted on the commercial for the movie.

The Internet is a large part of the synergistic strategy, encouraging an "inter-media" commodity flow, or an "overflow" (Brooker, 2001). The major children's programming players all have websites aimed at children (disney.com, foxkids.com, kidswb.com, cartoonnetwork.com, nick.com), and sometimes more than one; toonami.com, a Time Warner website hyped by both WB and Cartoon Network, for example, is devoted to action cartoons and anime. These sites are promoted through bugs (that often transform from the corporate name to the website address), squeezed credits, and their own promotional spots.

Such sites help to extend the brand, create sites to sell merchandise, and further encourage the flow of audiences through corporate programming. In a promotional spot for both The Mummy and kidswb.com that was shown on WB 2002, a contest is touted called "Ask Imhotep." The spot is shown at 9:52, during The Mummy, and repeated at 10:17. The narrator says, "Kids WB is giving you a chance to ask Imhotep

Table 6 Instances of Visual Appearance and Vocal Mentions of "Disney" on ABC, 8-11 am, January 26, 2002

\begin{tabular}{lcc}
\hline Content type & Visual appearance & Vocal mention \\
\hline Program title/opening credits & 9 & 0 \\
Program ending credits & 16 & 6 \\
Program separators & 43 & 43 \\
Product advertisements & 8 & 4 \\
Program promotions & 32 & 11 \\
Network/station ID & 6 & 0 \\
Public service announcements & 0 & 0 \\
Totals & 114 & 64 \\
\hline
\end{tabular}


[the Mummy's name] anything you want to know .... Go to kidswb.com and ask your question. And then watch Kids WB on Saturday, February 9th, and Imhotep might read your question on TV." This spot, then, directs audiences from the TV to the Internet (where on-line shopping opportunities exist) and back to the TV. A similar tactic is used by the Cartoon Network in its 2002 Batman/Superman voting competition where viewers can "go to toonami.com, choose your favorite [character], and play them in a new on-line game... The winner is announced at 5 [on Cartoon Network]." One difference, as the narrator in a later version of the spot informs us, is that this network/Internet promotion is also a type of product ad, because it is "Brought to you by Gatorade ... Is it in You?" In fact, the narrator for this promotion, although of course uncredited, sounds very much like Kevin Conroy, the actor who is the voice for Batman and has narrated earlier, stand-alone Gatorade commercials. This promotional spot pulls extra duty, plugging with the same images and sounds: (1) Cartoon Network; (2) Batman licenses; (3) Superman licenses; (4) DC Comics (owned by Time Warner); (5) the toonami brand and website; and (6) Gatorade.

\section{Conclusion}

This analysis of commodity flow on children's television shows the intrusion of selling and branding strategies across many content forms, and the erosion of distinctions between these forms that this intrusion fosters. The heavy commercialism found throughout the history of U.S. children's television notwithstanding, the increasingly strategic nature of commodity flow and the promotional synergy of entertainment corporations add levels of integration. Specific forms of flow subvert policy restrictions designed to decrease commercialism. Program separators and PSAs, for instance, become part of the branding mix rather than barriers to commercial blurring.

Both samples showed strong indicators of flow. However, even in the modest time that elapsed between 2000 and 2002, increases in promotional flows may be seen. Although the 2000 sample featured the visibility of collector programs like Pokémon and Digimon that were nearing the end of their reign, the 2002 sample offered more systematic integration of cross-promotion between corporate holdings, such as the multi-licensed promotion of Jimmy Neutron and the repurposing (Sandler, 2003, 2004) of programs like Lizzie McGuire from the Disney Channel to ABC, promoting and branding the former while decreasing production costs for the latter. Web addresses and promotions of websites were frequent in 2000, but the strategic movement of children to commercially friendly sites—such as the Mummy and Superman/Batman "contests" mentioned above-indicates that new techniques are evolving to fully integrate the Internet.

As noted earlier, some critics of the concept of television flow claim that it essentializes television and masks key distinctions among content categories found on television (discussed in Corner, 1999). In fact, there were moments of disjunction in the sample. Many PSAs were more sedate, shorter, and less sales-oriented than many of the forms around them, such as a 10-second PSA for the music-oriented website 
playmusic.org (ABC, 2002, 9:51, repeated at 10:31). Especially on the cable networks, an occasional "old school" commercial featured a traditional authoritarian male narrator discussing an educational product targeted more to parents than children, such as a two-minute long Zoobooks commercial on the Cartoon Network, at 8:41am in 2002. But these differences were rare in the larger promotional environment, which featured other forms that were more synergistically and stylistically a part of the flow.

Another criticism of flow research is that it is typically "source-biased," and does not take into account the variability in reception contexts and interpretative frameworks that audiences bring to bear (see Budd et al., 1999). In particular, Seiter (1993) argues that children are perhaps more sophisticated television viewers than many researchers assume. It is true that this study did not analyze audience reception of flow, and no doubt children vary in how they view the images targeted to them.

Yet implied by this analysis is a concern about differences in social power between sources and audiences in children's television. Through collective ownership, media corporations are increasingly joined; audience members are isolated from each other. Corporations have collected much proprietary research about audience behavior, research that they are not compelled to make public. Children collectively have significant purchasing influence, but little political influence. Perhaps more significantly, children's self-concept is still being formed, while advertising and media brands have been solidly formed through a torrent of marketing research and branding messages. Children face waves of images of themselves and things they love that are increasingly connected together by a dominant message: "You should buy/watch this as part of being a kid." What, then, does this power difference between sources and audiences lead to? Although more research is needed, evidence exists that children's advertising may cultivate materialistic values among young viewers (Smith \& Atkin, 2003). As media synergy and branding have come to dominate children's television as much if not more than more traditional toy and cereal advertising, the message of "you are what you watch" may contribute to the historically commodified ethos of product advertising by encouraging the purchasing and consuming of media products that connect so many different content forms.

More precise and assertive policy may help considerably. So may the viewing context. Parents as mediators - watching television with their children, for examplecan blunt the cultivation of material values with children's television viewing (Smith \& Atkin, 2003). But constantly evolving forms of promotion challenge the effectiveness of slow-moving policy development and the role of adult mediators. Much of the research about the effects of children's television examines the extent to which children can distinguish between commercials, which primarily have a selling function, and programs, which primarily have entertainment or educational function (Smith \& Atkin, 2003). How do parents respond when there is little distinction? What happens when devices that were mandated to circumscribe the selling function (like program separators and PSAs discussed earlier) actually enhance it through their integration with branding strategies? How may regulation deal with new, more subtle forms of selling and promotion that are difficult to separate from other television forms, and that seem designed to undermine existing policy? Children may be at risk of growing 
up in a world with fewer "ad-free" cultural zones, zones that can serve as important high ground above commodity tidal waves.

\section{Note}

[1] One author analyzed all of the programming from the 2000 tapes, and the 2002 programming was divided up for analysis by the two authors (with one author taking ABC, Cartoon Network, and the WB; and the other taking FOX and Nickelodeon). Although the primary method is not a quantitative content analysis per se, training and double checks were conducted to increase the validity of the analysis. The researchers discussed their notes and analysis of textual characteristics. In addition, one stretch of programming was viewed by both researchers to check for similarities in uncovering textual nuances and similarities. Finally, the separate notes of the two researchers were compared for agreement when the same commercial or other program type was analyzed by both researchers, a common occurrence given the repetition found in children's television.

\section{References}

Alexander, A., Benjamin, L. M., Hoerrner, K., \& Roe, D. (1998). 'We'll be back in a moment': A content analysis of advertisements in children's television in the 1950s. Journal of Advertising, 27, 3, 1-9.

Andersen, R. (1995). Consumer culture and TV programming. Boulder, CO: Westview Press.

Bagdikian, B. (2004). The new media monopoly (7th ed.). Boston: Beacon.

Bellamy, R. V., \& Walker, J. R. (1996). Television and the remote control: Grazing on a vast wasteland. New York: Guilford.

Bernstein, P. (2001, December 17). Ayem kid biz losing fizz. Variety, 30-31.

Brooker, W. (2001). Living on Dawson's Creek: Teen viewers, cultural convergence, and television overflow. International Journal of Cultural Studies, 4, 456-472.

Budd, M., Craig, S., \& Steinman, C. (1999). Consuming environments: Television and commercial culture. New Brunswick, NJ: Rutgers University Press.

Christians, C. G., \& Carey, J. W. (1989). The logic and aims of qualitative research. In G. H. Stempel III, \& B. H. Westley (Eds.), Research methods in mass communication (2nd ed., pp. 354-374). Englewood Cliffs, NJ: Prentice-Hall.

Corner, J. (1999). Critical ideas in television studies. Oxford: Clarendon.

Dempsey, J. (2001a, September 3). Disney Channel primo with tweens. Variety, p. 24.

Dempsey, J. (2001b, May 28-June 3). Fox Family put up for adoption. Variety, 13-14.

Finnigan, D. (2002, June 17). When it comes to pitching properties almost everything old is new again. Brandweek, pp. 10-11.

Giroux, H. A. (2001). The mouse that roared: Disney and the end of innocence. New York: Rowman and Littlefield.

Hall, W. J. (2000, April 10). The toys are back in town. Variety, p. 55.

Jacobson, N. F., \& Mazur, L. A. (1995). Marketing madness: A survival guide for a consumer society. Boulder, CO: Westview.

Kapur, J. (1999). Out of control: Television and the transformation of childhood in late capitalism. In M. Kinder (Ed.), Kids' media culture (pp. 122-128). Raleigh, NC: Duke University Press.

Kinder, M. (1999). Ranging with power on the Fox Kids Network: Or, where on earth is children's educational television? In M. Kinder (Ed.), Kids' media culture (pp. 177-203). Raleigh, NC: Duke University Press. 


\section{M. P. McAllister \& J. M. Giglio}

Kline, S. (1993). Out of the garden: Toys and children's culture in the age of TV marketing. London: Verso.

Kunkel, D. (2001). Children and television advertising. In D. G. Singer, \& J. L. Singer (Eds.), Handbook of children and the media (pp. 375-393). Thousand Oaks, CA: Sage.

Kunkel, D., \& McIlrath, M. (2003). Message content in advertising to children. In E. L. Palmer \& B. M. Young (Eds.), The faces of televisual media: Teaching, violence, selling to children (2nd ed., pp. 287-300). Mahwah, NJ: Erlbaum.

Larson, M. (2001, August 13). Kids anticlimax: Upfront is a dud. Mediaweek, p. 4.

McAllister, M. P. (1996). The commercialization of American culture: New advertising, control and democracy. Thousand Oaks, CA: Sage.

McAllister, M. P. (2000). From flick to flack: The increased emphasis on marketing by media entertainment corporations. In R. Andersen, \& L. A. Strate (Eds.), Critical studies in media commercialism (pp. 101-122). New York: Oxford University Press.

McChesney, R. W. (1999). Rich media, poor democracy: Communication politics in dubious times. Urbana, IL: University of Illinois Press.

McDonald, M., \& Lavelle, M. (2001, July 30). Call it 'kid-fluence... U.S. News and World Report, p. 32.

Mittell, J. (2003). The great Saturday morning exile: Scheduling cartoons on television's periphery in the 1960s. In C. A. Stabile, \& M. Harrison (Eds.), Prime time animation: Television animation and American culture (pp. 33-54). New York: Routledge.

Modleski, T. (1983). The rhythms of reception: Daytime television and women's work. In E. A. Kaplan (Ed.), Regarding television: Critical approaches-an anthology (pp. 67-75). Los Angeles: The American Film Institute.

Pecora, N. (1998). The business of children's entertainment. New York: Guilford.

Pecora, N. (2004). Nickelodeon grows up: The economic evolution of a network. In H. Hendershot (Ed.), Nickelodeon nation: The history, politics, and economics of America's only TV channel for kids (pp. 15-44). New York: New York University Press.

Sandler, K. S. (2003). Synergy nirvana: Brand equity, television animation, and Cartoon Network. In C. A. Stabile, \& M. Harrison (Eds.), Prime time animation: Television animation and American culture (pp. 89-109). New York: Routledge.

Sandler, K. S. (2004). 'A kid's gotta do what a kid's gotta do': Branding the Nickelodeon experience. In H. Hendershot (Ed.), Nickelodeon nation: The history, politics, and economics of America's only TV channel for kids (pp. 45-68). New York: New York University Press.

Schmuckler, E. (2002, April 1). Looking for a fight. Mediaweek, pp. 23-26.

Seiter, E. (1993). Sold separately: Children and parents in consumer culture. New Brunswick, NJ: Rutgers University Press.

Smith, S. L., \& Atkin, C. (2003). Television advertising and children: Examining the intended and unintended effects. In E. L. Palmer, \& B. M. Young (Eds.), The faces of televisual media: Teaching, violence, selling to children (2nd ed., pp. 301-325). Mahwah, NJ: Erlbaum.

Smythe, D. (1977). Communications: Blindspot of western Marxism. Canadian Journal of Political and Social Theory, 1, 3, 1-27.

Tobin, J. (2004). Introduction. In J. Tobin (Ed.), Pikachu's global adventure: The rise and fall of Pokémon (pp. 3-11). Durham, NC: Duke University Press.

Williams, R. (1975). Television: Technology and cultural form. New York: Schocken.

Received May 7, 2004

Accepted June 13, 2004 